tions in $\mathrm{UC}, \mathrm{UC}_{2}$ and $\mathrm{U}_{2} \mathrm{C}_{3}$ were described, and led the authors to conclude that both vacancies and interstitials or elusters of these are formed, and that there appears to be a definite saturation effect at low burn-up. At higher burn-up the damage is more complex and there is an indication that the defect aggregates are more stable.

Irradiation experiments on miniature fuel elements at centre temperatures between $700^{\circ}$ and $1,400^{\circ} \mathrm{C}$ and burn-ups between 1,000 and 30,000 MW days/tonne were reported by authors from the Argonne, United Nuclear and Harwell Laboratories. In general, the release of fission gas from single phase UC and (UPu)C fuel is low, and in some cases it is much less than the amount that would be expected from recoil alone. Work on U-C has shown that the release of fission gas is influencod by the nature of the second phase present as a result of deviations from the stoichiometric amount of carbon, hypostoichiometric alloys releasing much more gas than hyperstoichiometric alloys. Irregular cracking has been observed in many irradiated carbide samples, but it is not clear whether these cracks are present prior to irradiation. The presence of these cracks does not seem to have had any deleterious effects and no significant changes in microstructure have been reported.

Electron microscopy of irradiated carbides has brought to light the precipitation of fission gas bubbles in the free uranium areas in hypostoichiometric uranium-carbon alloys. This suggests that the free metal behaves like bulk uranium and may be responsible for swelling in hypostoichiometric alloys.

Sayers described the irradiation behaviour of coated particle fuels to the very high burn-up of 14 per cent. The results provided useful information on the irradiation behaviour of $\mathrm{UC}_{2}$, which can retain fission gases and hold 99 per cent of the amount generated even in particles with failed coatings. A spearhead form of attack, resulting in the formation of characteristic V-shaped cracks extending radially outwards into the pyrocarbon coatings, was reported. 'This is believed to result from the irradiation-induced shrinkage of the low-density pyrocarbon.

The symposium will undoubtedly prove to be important in the development of carbide fuels for nuclear reactors. The large number of papers presented and the widespread interest in the conference give a clear indication of the eagerness with which the arrival of carbides as viable fuels is awaited. It is now apparent that carbides of controlled composition ean be made by any of several variations of two basic routes and that rather detailed investigations of all the relevant phase equilibria and physical and chemical properties are now being undertaken. However, it is always the case that the final proof of any nuclear fuel material arrives at a much later stage than this. The irradiation results that have appeared are, on the whole, extremely promising, but it remains to be demonstrated that carbides are superior in overall performance to oxides.

\title{
BIOCHEMISTRY IN SPAIN
}

$\mathrm{T}$ HE development of biochemistry in Spain over the past two decades has been hindered by various factors, notably the isolation of the country during and after the Spanish Civil War and tho Second World War, the loss of talent through emigration of a large proportion of the more promising scientists, and the inadequacy of the educational programmes, particularly in the medical schools, where the teaching of biochemistry is still largely in the hands of physiologists.

The establishment of some units for biochemical research in the 'fifties, under the sponsorship of the Consejo Superior de Investigaciones Cientificas (C.S.I.C.), was the starting-point of steady improvement in that area. Several factors which have positively contributed to this development are the increasing flux of young biochemists from Spain to the United States, Great Britain and other countries for further training and the support provided by the private Foundation 'Juan March' and, more recently, by the U.S. Public Health Service to some local groups. Moreover, whereas biochemistry was formerly taught at the undergraduato-level only in the university faculties of pharmacy, somo new chairs of biochemistry have now been created in faculties of science.

A first meeting of Spanish biochemists, under the auspices of the C.S.I.C. and the International University Monendez y Pelayo, was held at Santander in July 1961, and a second meeting, under the sponsorship of the C.S.I.C. and the University of Santiago de Compostela, was held in Santiago during August 1-3.

The latter meeting was attended by about a hundred sciontists, thirty of whom presented papers dealing with their recent work in Spain or abroad. Five formal lectures were delivered by Prof. M. Lora Tamayo, professor of organic chemistry in the University of Madrid and Minister of Education, on the active site and the mechanism of action of phosphatases; Dr. A. Sols, head of the Department of Enzymology of the Instituto Marañon, C.S.I.C., Madrid, on metabolie control of enzymo activity; Prof. J. Oró, University of Houston, Texas, on the synthesis of biochemical compounds under prebiotic-like conditions; Prof. L. F. Leloir, Institute of Biochemical
Research, Buenos Aires, on sugar nucleotides and polysaccharide synthesis; and Prof. S. Ochoa, New York University, on the genetic code. Communications were presented by Drs. F. Alvarado, C. Asensio, J. L. R.-Candela, F. Escobar, Gertrudis de la Fuente, Carmon Garcia, C. F. Heredia, M. Losada, F. Mayor, Gabriela Morreale, Monique Novaes, A. Paneque, D. Rodriguoz, Margarita Salas, J. Vicente, J. R. Villanueva, E. Viñuela and F. Vivanco (Madrid); Drs. F. Calvet, E. Cuenca, P. PuigMuset, and M. Rosell (Barcelona); Drs. J. A. Cabezas and B. Regueiro (Santiago); Dr. E. Montoya (Granada); Dr. E. Santiago (Pamplona); Dr. F. Sabater (Long Ashton, Bristol); Dr. D. Vazquez (Cambridge); Dr. C. Osorio (Birmingham); and Dr. T. Jauregui-Adell (Paris). Prof. C. Jimenez Diaz, the noted Spanish clinician, gave a résumé of the meeting at its closing session and emphasized the increasing impact of biochemical investigations in the advance of clinical research.

At the request of the Spanish National Committee for Biochemistry (Spain's representative body on the International Union of Biochemistry), a group of biochemists, as charter members, formally founded a Spanish Society of Biochemistry in Santiago. The first Council of the new Society was appointed as follows: Dr. A. Sols (president), Prof. F. Calvet (vice-president), Dr. J. Rodriguez Villanueva (secretary), Dr. M. Losada (treasurer), Dr. E. F. Alvarez, Prof. J. Garcia Blanco, Prof. F. Mayor, Prof. J. L. Rodriguez-Candela, Prof. S. Santos Ruiz, Dr. F. Vivanco (officers), and Dr. C. Asensio (secretary elect). Prof. C. Jimenez Diaz, Prof. L. F. Leloir, Prof. M. Lora Tamayo, and Prof. S. Ochoa, were appointed honorary members. The addross of the new Society is: Centro do Investigaciones Biológieas, Velázquez 138, Madrid 6, Spain.

The Society aims at furthering the progress of bioehemistry in Spain by holding scientific meetings and by the intensive promotion of relations between biochemists in Spain and abroad. To this end tho Society will seek admission in the newly created Furopean Federation of Biochemical Societies.

\section{J. Rodríguez. Villanufia} C. Asensio 